\title{
Kish Graphite Flakes as a Cathode Material for an Aluminum Chloride-Graphite Battery
}

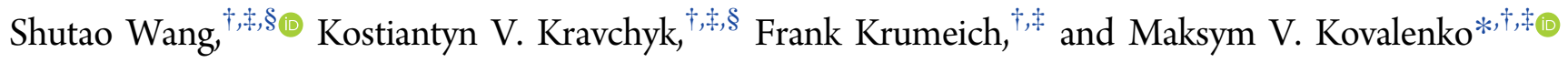 \\ ${ }^{\dagger}$ Laboratory of Inorganic Chemistry, Department of Chemistry and Applied Biosciences, ETH Zürich, Vladimir-Prelog-Weg 1, \\ CH-8093 Zürich, Switzerland \\ ${ }^{*}$ Laboratory for Thin Films and Photovoltaics, Empa - Swiss Federal Laboratories for Materials Science and Technology, \\ Überlandstrasse 129, CH-8600 Dübendorf, Switzerland
}

\section{Supporting Information}

ABSTRACT: Nonaqueous, ionic liquid-based aluminum chloride-graphite batteries $\left(\mathrm{AlCl}_{3}-\mathrm{GBs}\right)$ are a highly promising post-Li-ion technology for low-cost and large-scale storage of electricity because these batteries feature exclusively highly abundant chemical elements and simple fabrication methods. In this work, we demonstrate that synthetic kish graphite, which is a byproduct of steelmaking, can be used as a cathode in $\mathrm{AlCl}_{3}-\mathrm{GB}$ and exhibits high capacities of $\leq 142$ $\mathrm{mAh} \mathrm{g}^{-1}$. The comprehensive characterization of kish graphite flakes and other forms of graphite by X-ray diffraction, Raman spectroscopy, and Brunauer-Emmett-Teller surface area analysis provides solid evidence that the exceptional electrochemical behavior of kish graphite flakes is mainly determined by the high structural order of carbon atoms, a low level of defects, and a unique "crater morphology". In view of the nonrocking chair operation mechanism of $\mathrm{AlCl}_{3}-\mathrm{GB}$, we have tested the achievable energy densities as a function of the composition of chloroaluminate ionic liquid $\left(\mathrm{AlCl}_{3}\right.$ content) and have obtained energy densities of up to $65 \mathrm{Wh} \mathrm{kg}^{-1}$. In addition, the kish graphite flakes can rapidly charge and discharge, offering high power densities of up to $4363 \mathrm{~W} \mathrm{~kg}^{-1}$.

KEYWORDS: aluminum chloride-graphite battery, aluminum, kish graphite, flake, energy density

\section{INTRODUCTION}

Renewable sources of electricity, such as biomass, hydropower, geothermal, solar, and wind, hold an increasing share in the overall world production of electricity (summing to ca. $19 \%$ in 2016). ${ }^{1,2}$ Among these sources, the fastest-growing contribution comes from the intermittent renewables, such as solar and wind, which may, however, destabilize the electrical grid because of the production-consumption mismatch. ${ }^{3,4}$ In the context of developing smart electrical grids, large and inexpensive stationary rechargeable batteries will play an increasing role in addition to the more traditional pumped hydroelectric storage (PHS). ${ }^{5}$ In the applications of batteries in portable electronics (smartphones, tablets, laptops) and mobility (trains, buses, cars, bikes, scooters), the energy and power densities prevail over cost, whereas in stationary batteries, the situation is entirely reversed. For example, presently, $99.3 \%$ of all of the stationary storage systems are based on PHS because of its notably low capital cost (0.1-1.4 $\$ / \mathrm{kWh}$ per cycle) in comparison to batteries $(15-100 \$ / \mathrm{kWh}$ per cycle for Li ion; see Supporting Information for a more detailed comparison, Figure S1) despite its low energy density (0.5-1.5 Wh kg-1 for PHS vs 75-200 Wh kg-1 for Li-ion battery). ${ }^{5}$ The realization of such stringent cost requirements is possible only when the batteries comprise exclusively of inexpensive components based on naturally abundant elements and are produced using the utmost simple processes.

Toward this goal, in recent years, various chemistries have been explored based on nontoxic and earth-abundant elements such as $\mathrm{Na},{ }^{6-9} \mathrm{~K},{ }^{10} \mathrm{Ca},{ }^{11} \mathrm{Mg},{ }^{12-14}$ and $\mathrm{Al}^{15-21}$ In particular, much attention has been paid to the development of $\mathrm{Al}$ batteries, where $\mathrm{Al}$ can be used in its convenient and inexpensive metallic form on the anodic side, which benefits from the highly reversible metal stripping/plating. ${ }^{22}$ Thus, various rocking-chair-type batteries are currently being explored, where the reversible insertion of $\mathrm{Al}^{3+}$ into the cathodes based on transition metal sulfides (from $\mathrm{Fe}^{23} \mathrm{Ni}^{24,25} \mathrm{~V}$, $\mathrm{Mo}^{31} \mathrm{Mn}^{32} \mathrm{Cu}^{33}$ ) and oxides is assumed. However, in practice, reversible intercalation of highly charged $\mathrm{Al}^{3+}$ ions in any host structure is extremely difficult because of the high ionic charge density $\left(\mathrm{Al}^{3+}\right.$ is even smaller than $\left.\mathrm{Li}^{+}\right)$, which renders low ionic diffusivity and causes other difficulties such as the solvation and desolvation of ions. ${ }^{34}$ In contrast, the facile reversible intercalation is afforded with monovalent species, such as $\mathrm{AlCl}_{4}^{-}$, as shown in the 1970s by Fouletier et al., ${ }^{35}$ who reported the electrochemical intercalation of $\mathrm{AlCl}_{4}^{-}$ions into

Received: May 26, 2017

Accepted: August 2, 2017

Published: August 2, 2017 


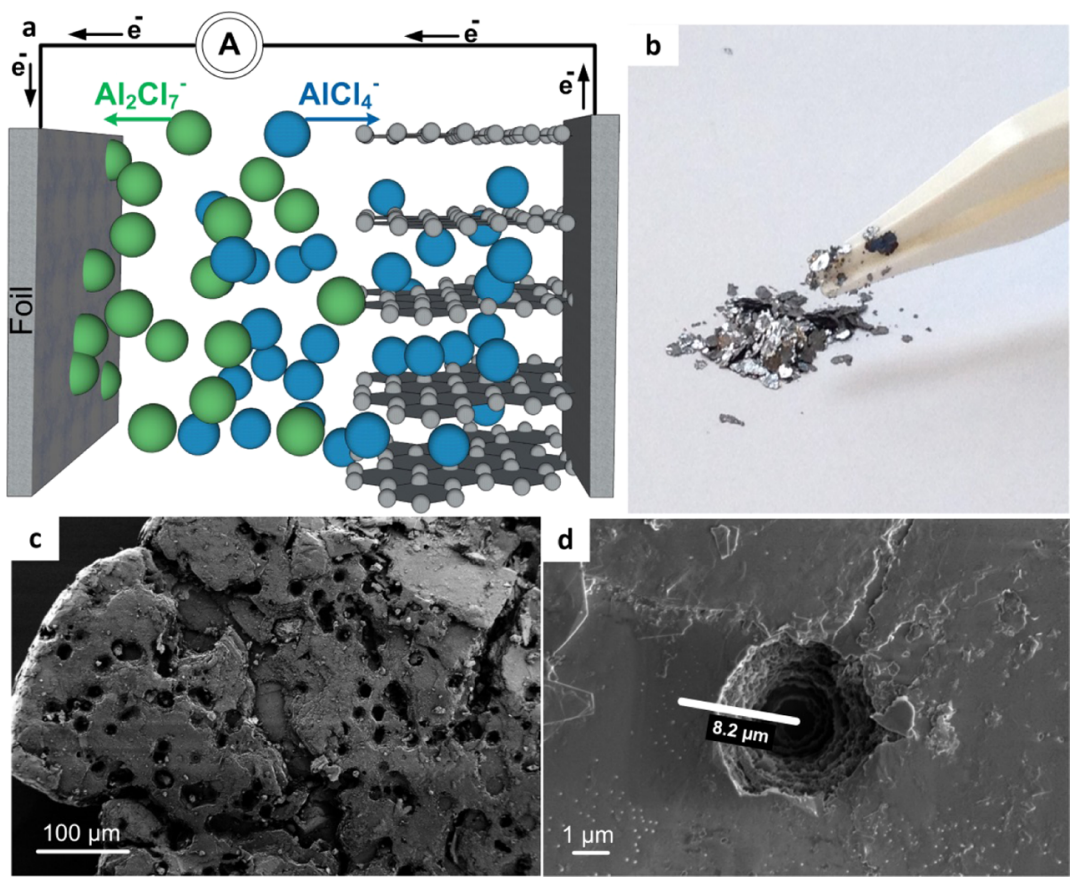

Figure 1. "Aluminum chloride-graphite battery" $\left(\mathrm{AlCl}_{3}-\mathrm{GB}\right)$. (a) Schematic image of an aluminum chloride-graphite battery during charging. Optical (b) and scanning electron microscopic (SEM) (c, d) images of the kish graphite flakes. The kish graphite flakes comprise small 5-10 $\mu \mathrm{m}$ deep holes, which facilitate the penetration of the ionic liquid within the flake.

graphite from the molten salt $\left(\mathrm{LiCl} / \mathrm{AlCl}_{3} ; \mathrm{ca} .140{ }^{\circ} \mathrm{C}\right)$. In this system, graphite acts as a cathode that is oxidized at a potential of 1.5-2.1 V versus metallic $\mathrm{Al}\left(\mathrm{Al}^{3+} / \mathrm{Al}\right)$. In 1988, Gifford et $\mathrm{al}^{36}$ extended such intercalation chemistry to construct a full cell, where the graphitic cathode and $\mathrm{Al}$ anode were immersed into a room temperature ionic liquid $\left(\mathrm{AlCl}_{3}\right.$ mixed with 1,2dimethyl-3-propylimidazolium chloride). We note that the authors of ref 36 assumed that $\mathrm{Cl}^{-}$ion intercalation occurred. In 2015, Lin et al. $^{37}$ further developed this concept, demonstrated a battery comprising pyrolytic graphite foil as a cathode in ionic liquid $\left(\mathrm{AlCl}_{3} / 1\right.$-ethyl-3-methylimidazolium chloride $(\mathrm{EMIMCl})$ ) at room temperature and reported a high reversibility over thousands of cycles and graphite cathodic capacities of up to $67 \mathrm{mAh} \mathrm{g}^{-1}$.

As depicted in Figure 1a, the following half-reactions occur during charging at the cathode (eq 1) and anode (eq 2)

$$
\begin{gathered}
x \mathrm{C}+\mathrm{AlCl}_{4}^{-} \rightarrow \mathrm{C}_{x}\left[\mathrm{AlCl}_{4}\right]+\mathrm{e}^{-} \\
4 \mathrm{Al}_{2} \mathrm{Cl}_{7}^{-}+3 \mathrm{e}^{-} \rightarrow \mathrm{Al}+7 \mathrm{AlCl}_{4}^{-}
\end{gathered}
$$

In the last 3 years, extensive efforts have concerned various forms of synthetic and natural graphite or materials derived from graphite, such as graphitic foams, ${ }^{37,38}$ graphene nanoribbons, ${ }^{39}$ few-layer graphene aerogels, ${ }^{40}$ graphene mesh network, ${ }^{41}$ large-sized few-layer graphene, ${ }^{42}$ and carbon paper (of graphitic nature), ${ }^{43,44}$ to maximize the cathodic charge-storage capacities and unravel the structure-electrochemical property relationship. Computational studies have shed light on the "staging mechanism" and diffusion of $\mathrm{AlCl}_{4}^{-}$, the geometry of inserted species, the degree of volumetric expansion, and so on. ${ }^{45-50}$

Recent experimental endeavors have focused on inexpensive natural graphite flakes, which demonstrate high charge-storage capacities of $110-150 \mathrm{mAh} \mathrm{g}^{-1}$ and high round-trip energy efficiencies (90\%). ${ }^{51,52}$ The major factors that govern the efficient uptake of $\mathrm{AlCl}_{4}{ }^{-}$ions are the flaky morphologies and high atomistic structural quality of these graphite particles. ${ }^{51}$ One reason for the beneficial effect of the flake geometry relates to the drastic expansion by up to $80 \%$ upon the insertion of large $\mathrm{AlCl}_{4}^{-}$anions, which is easily accommodated by increasing the flake thickness. Other shapes of graphite particles, such as potato-shaped graphite, which is successfully used in commercial Li-ion batteries, are characterized by folding, bending, or other geometric constraints. These shapes preclude the homogeneous expansion of the layers and consequently limit the achievable loads of $\mathrm{AlCl}_{4}{ }^{-}$ions. In addition to this form factor, the structural atomic or crystalline disorder, which is probed by Raman spectroscopy and X-ray diffraction (XRD), has been shown to exhibit profound effect on the uptake of $\mathrm{AlCl}_{4}{ }^{-}$ions. This result is in striking contrast to Li-ion storage, which is tested with identical graphitic electrodes. $^{51}$

These results have guided us to this work, wherein we tested a unique form of highly crystalline graphite, which closely resembles natural graphite flakes and is called kish graphite. Kish graphite is a synthetic, flake-shaped graphite available at the multiton scale as a byproduct of steelmaking. This type of graphite forms on the surface of molten iron upon its cooling because of the oversaturation of iron with carbon, which typically occurs in cast iron making or blast furnace processes (usually from hypereutectic compositions). ${ }^{53,54}$ As formed, kish graphite normally encases impurities of various oxides (slag) and iron. Purification by levitation and $\mathrm{HCl}$ acid removes nearly all impurities, and 95-99\% pure material remains. As shown in Figure $1 \mathrm{~b}$, kish graphite consists of millimeter-wide and dozenmicrometer-thick platelets. They often exhibit "crater morphology" with deep craters (holes), with the depth of up to half of the flake thickness depending on the formation conditions (Figure 1c,d). This material is increasingly recognized for its high crystallinity with known applications, including the production of graphene by mechanical exfoliation (crater-free 
grades must be chosen). It also holds considerable potential for the battery industry. ${ }^{55,56}$ In fact, the market of high-quality graphites in Li-ion batteries shows a global increase in the synthetic graphite contribution, which is currently $30 \%$ of the total amount of graphite used in the Li-ion batteries. ${ }^{57,58}$

In this work, we find that the electrochemical performance of the kish graphite in $\mathrm{AlCl}_{3}-\mathrm{GB}$ is at par with that of the topquality natural graphite flakes. Kish graphite delivers cathodic capacities of up to $142 \mathrm{mAh} \mathrm{g}^{-1}$. Furthermore, kish graphite flakes show exceptional rate capability, yielding high power densities of up to $4363 \mathrm{~W} \mathrm{~kg}^{-1}$. The latter can be explained by the unique combination of high crystallinity and its unique crater morphology, which enables a second insertion pathway for $\mathrm{AlCl}_{4}{ }^{-}$ions in addition to the edges of the flakes. Using the ionic liquid with the highest achievable $\mathrm{AlCl}_{3}$ content (2:1 $\mathrm{AlCl}_{3} / \mathrm{EMIMCl}$ ), the kish graphite flakes reach energy densities of $65 \mathrm{Wh} \mathrm{kg}^{-1}$, which is record high for $\mathrm{AlCl}_{3}-\mathrm{GB}$.

\section{RESULTS AND DISCUSSION}

Structural and Electrochemical Characterization of Kish Graphite Flakes. We have recently shown in a comparative study ${ }^{51}$ that the intercalation of large $\mathrm{AlCl}_{4}{ }^{-}$ions $(\sim 6.09 \AA)^{59}$ into graphite is significantly more sensitive to the structure, texture, and particle size of graphite than to those of smaller Li ions $(0.76 \AA) .{ }^{59}$ The associated volumetric expansion is also much greater ( 80 vs $10 \%$ ). Natural graphite flakes exhibit superior performance and deliver charge-storage capacities of 130-150 $\mathrm{mAh} \mathrm{g}^{-1}$ (higher for the constant current-constant voltage charging protocol, CCCV). Here, we extend the scope of cathode materials to kish graphites and provide a side-by-side comparison of the electrochemical and structural characteristics with other graphites [potato-shape graphite, natural graphite flakes of different sizes, and highly oriented pyrolytic graphite (HOPG)] and amorphous carbon (acetylene black).

The "crystalline perfection" of the graphite, which is a commonly used term, ${ }^{54,60}$ can be described as the minimization in the concentration of defects such as basal dislocations, nonbasal edge dislocations, prismatic screw dislocations and prismatic edge dislocations, non-s $\mathrm{p}^{2}$-bonded carbon atoms, and extrinsic impurities. Experimentally, the high level of crystalline perfection is proven by the nearly ideal interplanar d-spacing of $0.3354 \mathrm{~nm}$ (at room temperature) and low intensity of the Dband in the Raman spectra. Figure 1a shows the charge-storage capacities in a typical low-viscosity formulation of the used ionic liquid (1.3:1 $\mathrm{AlCl}_{3} / \mathrm{EMIMCl}$ ), wherein the tested carbons exhibit drastic differences. Figure $2 \mathrm{a}-\mathrm{c}$ shows that large-sized kish graphite flakes have the highest capacity values, the smallest interplanar $d$-spacing in their X-ray diffraction (XRD) patterns, and the lowest intensity of the D-band in the Raman spectra, which indicate the highest structural perfection.

The potato-shaped graphite particles exhibit much poorer structural quality, which can be considered at best a high intensity of the Raman D-band. Importantly, because of the unique crater morphology of the kish graphite flakes, they have a considerably larger Brunauer-Emmett-Teller (BET) surface area $\left(2.89 \mathrm{~m}^{2} \mathrm{~g}^{-1}\right)$ than the large natural graphite flakes $(0.03$ $\left.\mathrm{m}^{2} \mathrm{~g}^{-1}\right)$ of similar lateral size $(1-2 \mathrm{~mm}$; see also Table S1 and Figures S5 and S6). Much smaller natural graphite flakes and potato-shaped particles ( 8 and $30 \mu \mathrm{m}$, respectively) have similar BET surface areas (8.71 and $4.2 \mathrm{~m}^{2} \mathrm{~g}^{-1}$, respectively). The electrochemical measurements of kish graphite clearly indicate that, despite their relatively large sizes, charge-storage capacities, average discharge voltages, coulombic efficiencies, a
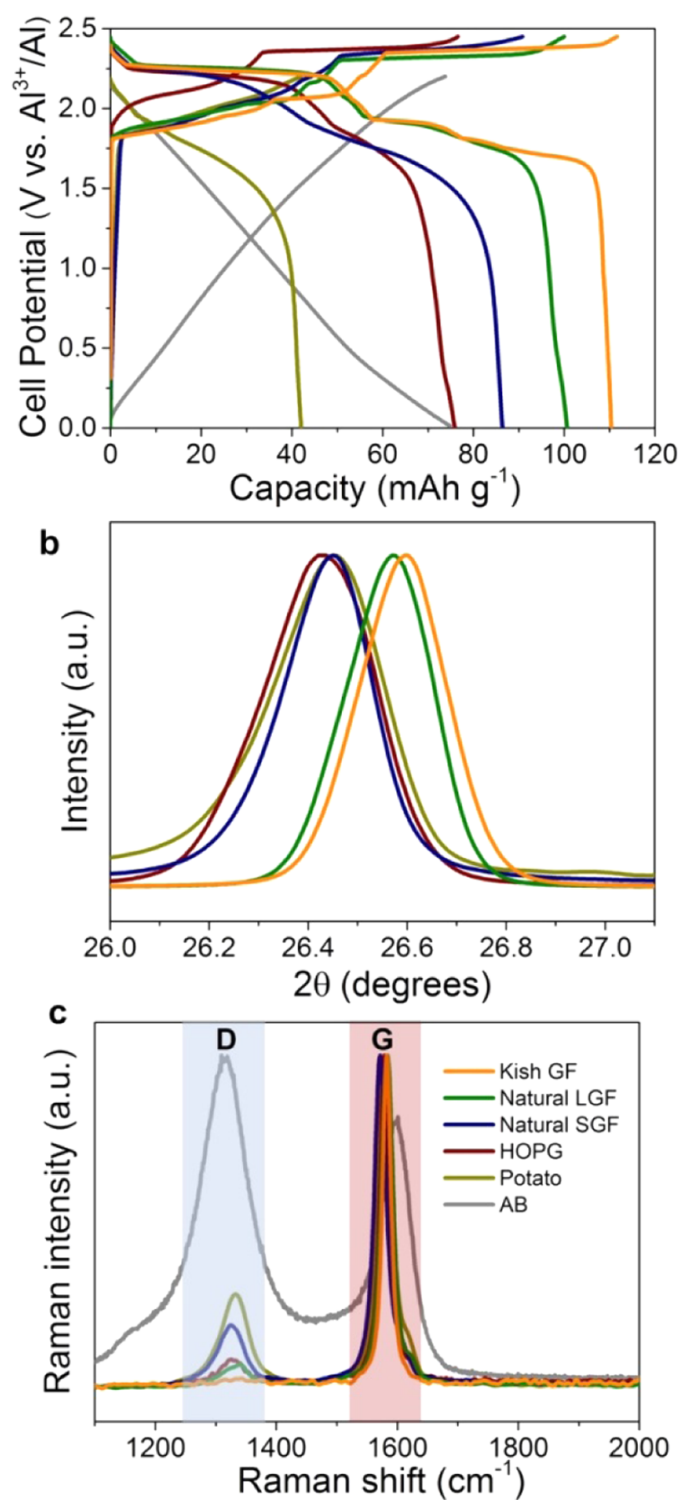

Figure 2. Characterization of various graphite materials [Kish GF, kish graphite flakes (2 mm); Natural LGF, natural large graphite flakes (1 $\mathrm{mm})$; Natural SGF, natural small graphite flakes $(8 \mu \mathrm{m})$; HOPG, highly oriented pyrolytic graphite; Potato, potato-shaped particles from MTI company $(30 \mu \mathrm{m}) ; \mathrm{AB}$, acetylene black $(26 \mu \mathrm{m})]$ in terms of electrochemical performance and crystalline perfection. The identical colors in the legend represent identical materials throughout all plots. (a) Measured galvanostatic charge and discharge voltage curves at the 20th cycle of various graphitic materials at $50 \mathrm{~mA} \mathrm{~g}^{-1}$ using $\mathrm{AlCl}_{3} / \mathrm{EMIMCl}$ at a $1.3: 1$ molar ratio. (b, c) X-ray diffraction and Raman spectroscopy measurements of various graphitic materials.

and energy efficiencies are the highest among all tested forms of graphite. Amorphous carbon exhibits lower capacities and sloppy voltage profiles. The latter resembles the intercalation of $\mathrm{Li}^{+}$into hard carbons, where the high charge-storage capacity is spread over broad range of potentials. ${ }^{61}$

Ex Situ XRD Probing of the Staging Mechanism. The staging mechanism of the $\mathrm{AlCl}_{4}^{-}$insertion into graphite has been computationally predicted ${ }^{62,63}$ and is apparent from the XRD patterns collected at various degrees of charging and discharging. The schematics of such staging are shown in Figure $\mathrm{S} 2$. $\mathrm{AlCl}_{4}{ }^{-}$ions do not insert into every graphite layer but in the 
superlative fashion to optimize the van der Waals forces between the graphene layers and the ionic repulsion among the $\mathrm{AlCl}_{4}{ }^{-}$ions. The lower stage number corresponds to the higher $\mathrm{AlCl}_{4}{ }^{-}$intercalant concentration and fewer empty graphenegraphene layers (see Figure S2). For the geometry of the inserted species, $\mathrm{Wu}$ et al. $^{45}$ suggested a single-layer, planar geometry of $\mathrm{AlCl}_{4}^{-}$ions with an intercalant gallery height $d_{\mathrm{i}}$ of $6.03 \AA$ (i.e., the distance between graphene-graphene layers). Jung et al. $^{46}$ proposed that the intercalant layer structure consisted of either a single layer of tetrahedral $\mathrm{AlCl}_{4}{ }^{-}$(stage 2) or the double-ion stacking of $\mathrm{AlCl}_{4}^{-}$(on top of each other) within the layer (stages 3 and 4) with $d_{\mathrm{i}}=8.5-12.2 \AA$. In contrast, several other groups ${ }^{47-49}$ suggested that the $\mathrm{AlCl}_{4}{ }^{-}$ intercalant prefers to adopt a single-layer tetrahedron geometry with the corresponding gallery height of $8.81,{ }^{47} 8.9^{48}$ or $8.36-$ $8.76 \AA{ }^{49}$ which remains nearly constant for all of the stages. ${ }^{49}$ Figure 3 shows the ex situ XRD patterns of the kish graphite flakes, which were collected and analyzed during the charge and discharge at different cutoff potentials (indicated by the numbers on the charge/discharge curves; see Table S2 for further details).

As shown in Figure $3 \mathrm{~b}$, the $002 \mathrm{XRD}$ reflection splits into two lines after charging, which clearly indicates the intercalation

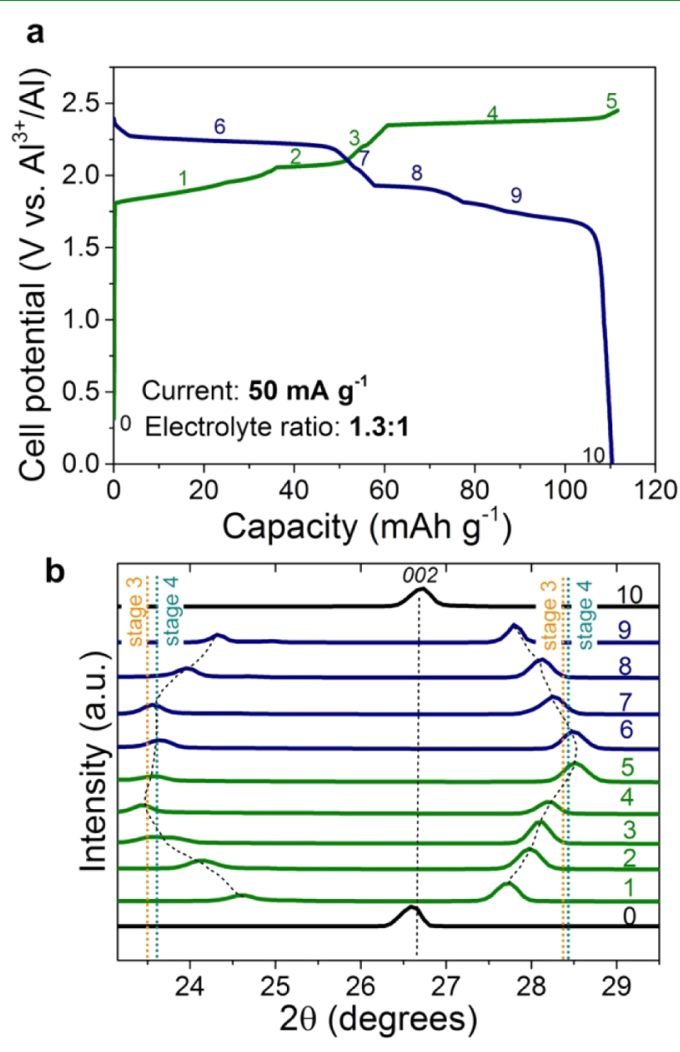

Figure 3. Ex situ XRD measurements of kish graphite flakes after charging and discharging, interrupted at various degrees. (a) Galvanostatic charge and discharge voltage curves of kish graphite flakes measured at $50 \mathrm{~mA} \mathrm{~g}^{-1}$ in 1.3:1 $\mathrm{AlCl}_{3} / \mathrm{EMIMCl}$ ionic liquid. (b) Ex situ X-ray diffraction patterns of kish graphite flakes. The numbers on the galvanostatic curves and XRD patterns correspond to different cutoff charging or discharging potentials of kish graphite flakes (see Table S2 for details). The dashed lines (orange and blue) in (b) correspond to the simulated XRD patterns for stages 3 and 4, which were calculated by Jung et al. ${ }^{46}$ and Gao et al. ${ }^{47}$ for a double-stacked layer ${ }^{46}$ and a single-layer tetrahedron geometry ${ }^{47}$ of $\mathrm{AlCl}_{4}{ }^{-}$, respectively. process. In accordance with the staging mechanism, an increase in the intercalant gallery height $d_{\mathrm{i}}$ and the periodic repeat distance $I_{c}$ (the distance between $\mathrm{AlCl}_{4}{ }^{-}$intercalant layers) with the stage number is visible by the appearance of two dominant peaks, which correspond to the planes $00 l$ and $00 l+1$, respectively. As estimated from the collected experimental XRD patterns upon charging, new 009 and 0010 planes appear at 1.8 $\mathrm{V}$ and evolve into 005 and 006 planes at $2.45 \mathrm{~V}$. Index $l$ was calculated using the following equation, which was derived from Bragg's law ${ }^{46}$

$$
l=\frac{1}{\frac{\sin \theta_{00 l+1}}{\sin \theta_{00 l}}-1}
$$

The XRD positions of the 005 and 006 reflections (23.57 and $28.51^{\circ}$ in $2 \theta$ units) are notably close to the calculated values (dashed line in Figure 3) for stages 3 or 4, which suggests either the double-stacked layer ${ }^{46}$ or a single-layer tetrahedron geometry. ${ }^{47}$ Hence, based on the relationships among $I_{\mathcal{c}}, d_{\mathrm{j}}$ and $l$, which can be expressed as $I_{\mathrm{c}}=l d_{00 l}=(l+1) d_{00 l+1}$ and $I_{\mathrm{c}}=$ $d_{\mathrm{i}}+(n-1) \times 3.35$, we can conclude that the intercalation of $\mathrm{AlCl}_{4}{ }^{-}$ions into kish graphite occurs with the increase in the graphene-graphene distance by up to 8.85 or $12.1 \AA$ (stage 3 or 4 ), depending on the geometry of the $\mathrm{AlCl}_{4}^{-}$ions in the layer.

Detailed Electrochemical Characterization, Power, and Energy Densities. Using the ionic liquid formulation in earlier tests in Figures $2 \mathrm{a}$ and $3 \mathrm{a}\left(1.3: 1 \mathrm{AlCl}_{3} / \mathrm{EMIMCl}\right)$, we tested the effect of the sonication-induced mechanical fragmentation of the flakes on their electrochemical performance (Figure S3). Such treatment decreased the lateral flake size to ca. $80 \mu \mathrm{m}$, which increases the BET surface area $\left(3.69 \mathrm{~m}^{2}\right.$ $\left.\mathrm{g}^{-1}\right)$. However, the structural perfection of the graphite was not compromised, as the experimental XRD $d$-spacing (3.359 $\AA$ ) and Raman spectra $\left(I_{\mathrm{D}} / I_{\mathrm{G}}=0.05\right.$; see also Table $S 1$ and Figure S4) show. In accordance with our earlier work, ${ }^{51}$ the CCCV charging protocol, which applies constant voltage steps at 1.92 and $2.07 \mathrm{~V}$, was also identified to improve the obtained capacities by $10-20 \mathrm{mAh} \mathrm{g}^{-1}$ (e.g., Figure S3).

Although the use of $1.3: 1 \mathrm{AlCl}_{3} / \mathrm{EMIMCl}$ ionic liquid enables one to compare the cathodic capacities with all of the previous reports on $\mathrm{AlCl}_{3}-\mathrm{GB}$, higher $\mathrm{AlCl}_{3}$ contents are required to maximize the energy density of the battery. Reaction 2, which relies on the existence of $\mathrm{Al}_{2} \mathrm{Cl}_{7}^{-}$ions, only occurs in acidic melts $\left(\mathrm{AlCl}_{3} / \mathrm{EMIMCl}>1\right) \cdot{ }^{64-66}$ Such melts can be $\mathrm{AlCl}_{3}$ dissolved in a neutral $\mathrm{AlCl}_{3} / \mathrm{EMIMCl}$ ionic liquid (1:1 molar ratio). The electroplating of $\mathrm{Al}$ will end upon depletion of this excessive $\mathrm{AlCl}_{3}$. For each electrodeposited $\mathrm{Al}$ atom, three $\mathrm{AlCl}_{4}{ }^{-}$anions intercalate into graphite. Therefore, reaction 2 can be reduced to

$$
\mathrm{AlCl}_{3}+\frac{3}{4} \mathrm{e}^{-} \leftrightarrow \frac{3}{4} \mathrm{AlCl}_{4}^{-}+\frac{1}{4} \mathrm{Al}
$$

$\mathrm{AlCl}_{3}$ can also be dissolved in other than EMIM-based media, as shown for $\mathrm{AlCl}_{3}$-urea, ${ }^{67,68}$ or fully inorganic $\mathrm{NaAlCl}_{4}$ melts. ${ }^{40}$ Apparently, the usage of a metallic $\mathrm{Al}$ anode is not necessary because any current collector that supports the initial electroplating of $\mathrm{Al}$ upon charging (reaction 4) or is coated with a thin seed $\mathrm{Al}$ film is sufficient. Thus, we refer to this battery as the aluminum chloride-graphite battery $\left(\mathrm{AlCl}_{3}-\mathrm{GB}\right)$ instead of "aluminum-ion"; we emphasize that the bare $\mathrm{Al}^{3+}$ ions do not intercalate into a graphitic cathode, and $\mathrm{AlCl}_{3}$ is an actual anodic material. The theoretical cell-level charge-storage 

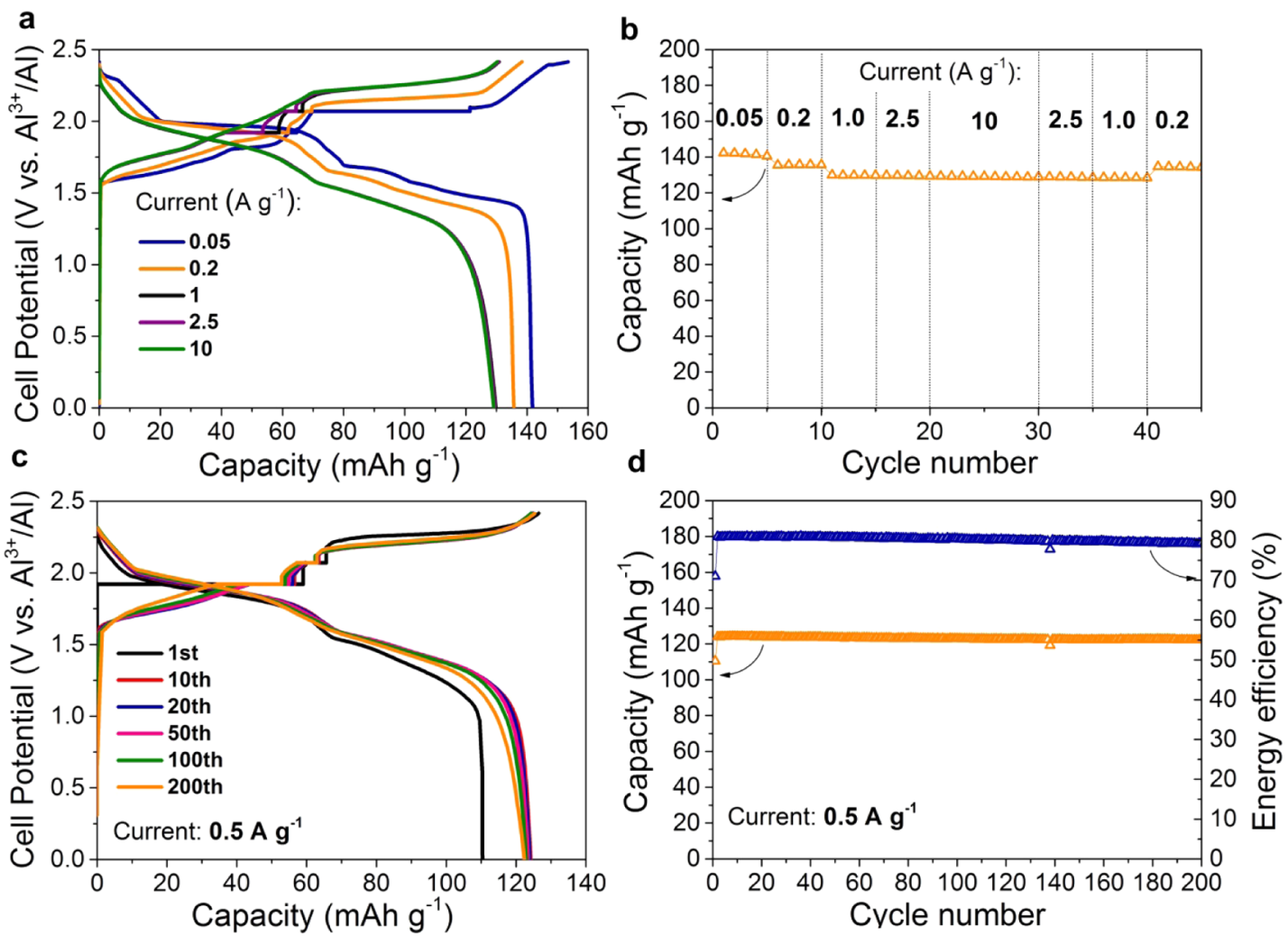

Figure 4. Electrochemical performance of sonicated kish graphite flakes in the $\mathrm{AlCl}_{3}-\mathrm{GB}$. (a, b) Galvanostatic charge-discharge voltage curves and rate capability tests measured with CCCV protocol at various current densities $\left(0.05-10 \mathrm{~A} \mathrm{~g}^{-1}\right)$ using 2:1 $\mathrm{AlCl}_{3} / \mathrm{EMIMCl}$ ionic liquid. (c, d) Galvanostatic charge-discharge voltage curves and cyclic stability of sonicated kish graphite flakes measured with CCCV protocol at $0.5 \mathrm{~A} \mathrm{~g}^{-1}$ using a 2:1 $\left(\mathrm{AlCl}_{3} / \mathrm{EMIMCl}\right)$ molar ratio.

capacity of any battery can be determined as $C_{\text {total }}=\frac{C_{A} C_{C}}{C_{A}+C_{C}}$, where $C_{\mathrm{A}}$ is the anodic capacity $\left(\mathrm{AlCl}_{3}\right)$ and $C_{\mathrm{C}}$ is the cathodic capacity (graphite). ${ }^{69,70}$

Clearly, because the $\mathrm{AlCl}_{3}$ / $\mathrm{EMIMCl}$ ionic liquid is both an electrolyte (i.e., transmitter of ions) and a source of electroactive species, its entire mass must be taken into derivation of the exact expression for $C_{\mathrm{A}}$ and, therefore, for the cell-level charge-charge storage capacity as follows

$$
\begin{aligned}
C_{\text {total }} & =\frac{F x(r-1) C_{c}}{F x(r-1)+C_{c}\left(r M_{\mathrm{AlCl}_{3}}+M_{\mathrm{EMIMCI}}\right)} \\
& =\frac{20.1(r-1) C_{\mathrm{c}} \times 10^{3}}{20.1(r-1) \times 10^{3}+C_{\mathrm{c}}\left(r M_{\mathrm{AICl}_{3}}+M_{\mathrm{EMIMCI}}\right)}
\end{aligned}
$$

where $F=26.8 \times 10^{3} \mathrm{mAh} \mathrm{mol}^{-1}$ (Faraday constant); $x=\frac{3}{4}$ (number of electrons used to reduce $1 \mathrm{~mol}$ of the anodic material, i.e., $\left.\mathrm{AlCl}_{3}\right) ; r$ is the $\mathrm{AlCl}_{3} / \mathrm{EMIMCl}$ molar ratio; $C_{\mathrm{C}}$ and $C_{\mathrm{A}}$ are the specific capacities of the cathode and anode, respectively, in $\mathrm{mAh} \mathrm{g}^{-1} ; \mathrm{M}_{\mathrm{AlCl}_{3}}$ is the molar mass of $\mathrm{AlCl}_{3}$ in $\mathrm{g}$ $\mathrm{mol}^{-1}$; and $M_{\mathrm{EMIMCl}}$ is the molar mass of EMIMCl or any other $\mathrm{Cl}^{-}$source to construct chloroaluminate ions from $\mathrm{AlCl}_{3}$.

Equation 5 enables one to assess the energy density of $\mathrm{AlCl}_{3}-\mathrm{GB}$ (energy density $=$ voltage $\times C_{\text {total }}$ ). Clearly, the $r$ values must be maximized, although this minimization usually leads to $10-20 \%$ lower cathodic capacities and discharge voltages. The natural-graphite-based batteries tested in our earlier work ${ }^{51}$ at the highest experimentally achievable $r$ of approximately 2 exhibited $C_{\mathrm{C}}$ of up to $123.5 \mathrm{mAh} \mathrm{g}$ and an average discharge voltage of approximately $1.77 \mathrm{~V}$, which yields an energy density of $\sim 62 \mathrm{Wh} \mathrm{kg}^{-1}$. The round-trip energy efficiency was shown to exceed $84 \% .{ }^{51}$ Because such a battery comprises exclusively of highly abundant chemical elements in its electrodes ( $\mathrm{Al}, \mathrm{Cl}, \mathrm{N}, \mathrm{C}$, and $\mathrm{H}$ ), it may become a viable technology for the stationary storage of electricity. Its energy density compares favorably with the major alternatives such as lead-acid batteries (30-50 $\mathrm{Wh} \mathrm{kg}^{-1}$; energy efficiency of 90\%) or vanadium redox-flow batteries (10-30 Wh $\mathrm{kg}^{-1}$; energy efficiency of $\sim 85 \%)^{5}{ }^{5}$

Analogous considerations and experiments (at $r=2, \mathrm{CCCV}$ charging protocol, Figure 4) for the $\mathrm{AlCl}_{3}-\mathrm{GB}$ based on the kish graphite yield energy densities of up to $65 \mathrm{Wh} \mathrm{kg}^{-1}$, as estimated from the capacities of $142 \mathrm{mAh} \mathrm{g}^{-1}$ and an average discharge voltage of $1.79 \mathrm{~V}$, which are obtained at a current density of $50 \mathrm{~mA} \mathrm{~g}^{-1}$ (Figure 4a). For comparison, with the conventional formulation of this ionic liquid $(r=1.3)$, the energy density of $\mathrm{AlCl}_{3}-\mathrm{GB}$ is limited to at most $33 \mathrm{Wh} \mathrm{kg}^{-1}$, with the cathodic capacity of $130 \mathrm{mAh} \mathrm{g}^{-1}$ and the average discharge voltage of $2 \mathrm{~V}$. Interestingly, sonicated graphite flakes have shown similar capacities of approximately $125 \mathrm{mAh} \mathrm{g}^{-1}$ at various discharge current densities $\left(1,2.5\right.$, and $\left.10 \mathrm{~A} \mathrm{~g}^{-1}\right)$, which indicates a unique rate capability of kish graphite (Figure 4a,b). The corresponding power density of $\mathrm{AlCl}_{3}-\mathrm{GB}$ reaches 4363 Wh $\mathrm{kg}^{-1}$. The cycling stability tests (Figure 4c,d) show a retention of capacities in excess of $120 \mathrm{mAh} \mathrm{g}^{-1}$, a stable energy efficiency of at least $80 \%$. The morphology of the flakes after cycling can be found in Figure S7. 


\section{CONCLUSIONS}

In this work, we have examined synthetic kish graphite as a cathode material for $\mathrm{AlCl}_{3}-\mathrm{GB}$. We have thoroughly compared kish graphite with natural graphite flakes, as well as with HOPG, potato-shaped graphite, and acetylene black. Specifically, we find a direct correlation between the structural characteristics (size, shape, XRD-determined d-spacing, apparent defectiveness in Raman spectra, and BET surface area) and the electrochemical performance. The intrinsically high structural perfection and unique crater morphology make kish graphite flakes a superior form of carbon to choose as a cathode for $\mathrm{AlCl}_{3}-\mathrm{GB}$.

$\mathrm{AlCl}_{3}-\mathrm{GB}$ operates via a nonrocking-chair mechanism, and its anodic capacity and the overall energy density are determined by the surplus of $\mathrm{AlCl}_{3}$ added to the neutral $\mathrm{AlCl}_{3} / \mathrm{EMIMCl}$ (1:1 molar ratio). Therefore, we tested the electrochemical performance of the kish graphite flakes at the highest achievable solubility of $\mathrm{AlCl}_{3} \quad\left(2: 1 \quad \mathrm{AlCl}_{3} / \mathrm{EMIMCl}\right.$ molar ratio). The corresponding charge storage capacity of the kish graphite flakes, which were pretreated by sonication, was up to $142 \mathrm{mAh} \mathrm{g}^{-1}$ and the average discharge voltage was 1.79 $\mathrm{V}$. This yields a high energy density of $65 \mathrm{Wh} \mathrm{kg}^{-1}$, which is thus far the highest value for $\mathrm{AlCl}_{3}-\mathrm{GB}$. Moreover, the kish graphite flakes can be cycled at high current densities of $10 \mathrm{~A}$ $\mathrm{g}^{-1}$, at which they still deliver a capacity of $124 \mathrm{mAh} \mathrm{g}^{-1}$ at an average discharge voltage of $1.6 \mathrm{~V}$, which corresponds to a high power density of $4363 \mathrm{~W} \mathrm{~kg}^{-1}$.

\section{EXPERIMENTAL SECTION}

Chemicals and Battery Components. Kish graphite flakes (grade 200, Graphene Supermarket), large natural graphite flakes (99.9\%, 10 mesh, Cat. No. 43319, Alfa Aesar), small natural graphite flakes (99\%, Cat. No. 43480, Alfa Aesar), highly oriented pyrolytic graphite (HOPG, 43836, Alfa Aesar), spherical graphite powder ("potato" graphite, 99.5\%, MTI Corporation), 1-ethyl-3-methylimidazolium chloride (EMIMCl, 99\%, Iolitec), $\mathrm{AlCl}_{3}$ (99\%, granules, Acros), Al foil (MTI Corporation), W plate (Bocheng Molybdenum Co., Ltd), and glass microfiber separator (GF/D, Cat No. 1823-257, Whatman) were used as received.

Preparation of the Chloroaluminate Ionic Liquid. Ionic liquid based on EMIMCl was prepared by slowly mixing the EMIMCl solid powder and $\mathrm{AlCl}_{3}$ granules in an argon-filled glovebox. During the mixing, a highly isothermal reaction occurred and eventually formed a light yellow liquid. Then, the ionic liquid was treated with $\mathrm{Al}$ foil at $150{ }^{\circ} \mathrm{C}$ for $6 \mathrm{~h}$ until a nearly colorless liquid was obtained. Because $\mathrm{AlCl}_{3} / \mathrm{EMIMCl}$ ionic liquid is very sensitive to the moisture, great care was taken to prevent the ionic liquid to come in contact with air. Even tiny traces of moisture caused the degradation of the electrochemical performance of the kish graphite flakes.

Sonication Treatment of the Pristine Kish Graphite Flakes. Commercial large graphite flakes $(0.2 \mathrm{~g})$ from Graphene Supermarket (grade 200) were placed into a $4 \mathrm{~mL}$ glass vial with $3.5 \mathrm{~mL}$ ethanol and sonicated for $30 \mathrm{~min}$ ( $10 \%$ power) using Sonopuls ultrasonic homogenizer HD2200. Then, the sonicated kish graphite flakes were washed three times with ethanol and dried in vacuum at $80{ }^{\circ} \mathrm{C}$ for 12 h.

Assembling and Testing the $\mathrm{AlCl}_{3}-\mathrm{GBs}$. All of the graphite samples were dried at $200{ }^{\circ} \mathrm{C}$ overnight in vacuum. No binders or solvents were used to prepare the electrodes. Homemade plastic cells were assembled in an argon-filled glovebox $\left(\mathrm{O}_{2}<1 \mathrm{ppm}, \mathrm{H}_{2} \mathrm{O}<1\right.$ $\mathrm{ppm})$ using three layers of glass fiber separator, which were soaked with $\mathrm{AlCl}_{3}$ /EMIMCl ionic liquid. The aluminum foil served as both reference and counter electrodes. A tungsten plate was used as the cathodic current collector. Then, $10 \mathrm{mg}$ (over ca. $1 \mathrm{~cm}^{2}$ ) of graphite material was homogeneously distributed on the surface of the glass fiber separator before covering with the tungsten current collector.
These cells were cycled between 0.01 and $2.45 \mathrm{~V}$ (for 1.3:1 molar ratio of ionic liquid) or 0.01 and $2.415 \mathrm{~V}$ (for 2:1 molar ratio of ionic liquid) on a MPG2 multichannel workstation (Bio-Logic). The CCCV protocol was used at 1.92 and $2.07 \mathrm{~V}$ until the current dropped to $10 \%$ of the initial value.

Structural Characterization of Graphite. Scanning electron microscopic (SEM) images were obtained with a M400 SEM microscope. The XRD patterns were recorded using a Bruker AXS D8 Advance X-ray diffractometer with Ni-filtered (2 mm thickness) $\mathrm{Cu} \mathrm{K} \alpha$ radiation $(\lambda=1.5406 \AA)$, which operated at $40 \mathrm{kV}$ and $40 \mathrm{~mA}$. Each sample was run at least twice using silicon as the internal standard. For ex situ X-ray diffraction (XRD) studies, the charged kish graphite flakes were removed from the cell inside the glovebox. To isolate from the atmosphere, the charged graphite samples were sealed between scotch films and brought into air shortly before the XRD measurements. The size of the potato- and flake-shaped graphite particles was determined using the small-angle light-scattering (SALS) instrument Mastersizer 2000 (Malvern, U.K.). The sample was diluted with anhydrous ethanol without filtration. Optical images were obtained using a LEICA M205 C microscope. The Raman spectroscopy measurements were performed on a high-resolution confocal Raman microscope (Ntegra Spectra, NT-MDT), which was equipped with a $632.8 \mathrm{~nm} \mathrm{HeNe}$ laser at an incident power of $1.7 \mathrm{~mW}$ for excitation at room temperature. The nitrogen adsorption isotherms were measured at $77 \mathrm{~K}$ and $10^{-3}-100 \mathrm{kPa}$ using a fully computerized Micromeritics ASAP 2020 instrument. The surface areas were calculated using the Brunauer-Emmett-Teller (BET) method with $P / P^{0}=0.005-1$. Prior to the measurements, the samples were degassed in vacuum $\left(10^{-1} \mathrm{mbar}\right)$ at $473 \mathrm{~K}$ for $12 \mathrm{~h}$ using a Micromeritics VacPrep 061 Sample Degas System.

\section{ASSOCIATED CONTENT}

\section{Supporting Information}

The Supporting Information is available free of charge on the ACS Publications website at DOI: 10.1021/acsami.7b07499.

Additional electrochemical, XRD, and BET data; optical and SEM images of kish graphite flakes (PDF)

\section{AUTHOR INFORMATION}

\section{Corresponding Author}

*E-mail: mvkovalenko@ethz.ch.

ORCID 우

Shutao Wang: 0000-0002-1689-2272

Maksym V. Kovalenko: 0000-0002-6396-8938

\section{Author Contributions}

${ }^{\S}$ S.W. and K.V.K. contributed equally to this work.

\section{Notes}

The authors declare no competing financial interest.

\section{ACKNOWLEDGMENTS}

We thank Dr. Michael Wörle for his assistance with the XRD measurements, Alberto Cingolani and Lu Jin for their assistance with SALS, and Feng Shao for his assistance with the Raman measurements. This work was financially supported by the Swiss Federal Commission for Technology and Innovation (CTI) through the CTI Swiss Competence Centers for Energy Research (SCCER, "Heat and Electricity Storage") and by the Competence Center for Energy and Mobility (CCEM, Project SLIB).

\section{REFERENCES}

(1) Ren21. Renewables. Global Status Report; Renewable Energy Policy Network for the 21st Century: Paris, 2016. 
(2) Weitemeyer, S.; Kleinhans, D.; Vogt, T.; Agert, C. Integration of Renewable Energy Sources in Future Power Systems: the Role of Storage. Renewable Energy 2015, 75, 14-20.

(3) Dunn, B.; Kamath, H.; Tarascon, J.-M. Electrical Energy Storage for the Grid: a Battery of Choices. Science 2011, 334, 928-935.

(4) Castillo, A.; Gayme, D. F. Grid-Scale Energy Storage Applications in Renewable Energy Integration: a Survey. Energy Convers. Manage. 2014, 87, 885-894.

(5) Chen, H.; Cong, T. N.; Yang, W.; Tan, C.; Li, Y.; Ding, Y. Progress in Electrical Energy Storage System: A Critical Review. Prog. Nat. Sci. 2009, 19, 291-312.

(6) Yabuuchi, N.; Kubota, K.; Dahbi, M.; Komaba, S. Research Development on Sodium-ion Batteries. Chem. Rev. 2014, 114, 1163611682.

(7) Wang, Y.; Chen, R.; Chen, T.; Lv, H.; Zhu, G.; Ma, L.; Wang, C.; Jin, Z.; Liu, J. Emerging Non-Lithium Ion Batteries. Energy Storage Mater. 2016, 4, 103-129.

(8) Singh, G.; Tapia-Ruiz, N.; Lopez del Amo, J. M.; Maitra, U.; Somerville, J. W.; Armstrong, A. R.; Martinez de Ilarduya, J.; Rojo, T.; Bruce, P. G. High Voltage Mg-doped $\mathrm{Na}_{0.67} \mathrm{Ni}_{0.3-\mathrm{x}} \mathrm{Mg}_{\mathrm{x}} \mathrm{Mn}_{0.7} \mathrm{O}_{2}(\mathrm{x}=$ $0.05,0.1)$ Na-ion Cathodes with Enhanced Stability and Rate Capability. Chem. Mater. 2016, 28, 5087-5094.

(9) Walter, M.; Bodnarchuk, M. I.; Kravchyk, K. V.; Kovalenko, M. V. Evaluation of Metal Phosphide Nanocrystals as Anode Materials for Na-ion Batteries. Chimia 2015, 69, 724-728.

(10) Eftekhari, A.; Jian, Z.; Ji, X. Potassium Secondary Batteries. ACS Appl. Mater. Interfaces 2017, 9, 4404-4419.

(11) Ponrouch, A.; Frontera, C.; Barde, F.; Palacin, M. R. Towards a Calcium-based Rechargeable Battery. Nat. Mater. 2016, 15, 169-172.

(12) Muldoon, J.; Bucur, C. B.; Gregory, T. Quest for Nonaqueous Multivalent Secondary Batteries: Magnesium and Beyond. Chem. Rev. 2014, 114, 11683-11720.

(13) Walter, M.; Kravchyk, K. V.; Ibáñez, M.; Kovalenko, M. V. Efficient and Inexpensive Sodium-Magnesium Hybrid Battery. Chem. Mater. 2015, 27, 7452-7458.

(14) Heath, J.; Chen, H.; Islam, M. S. MgFeSiO4 as a Potential Cathode Material for Magnesium Batteries: Ion Diffusion Rates and Voltage Trends. J. Mater. Chem. A 2017, 5, 13161-13167.

(15) Das, S. K.; Mahapatra, S.; Lahan, H. Aluminium-ion Batteries: Developments and Challenges. J. Mater. Chem. A 2017, 5, 6347-6367.

(16) Ambroz, F.; Macdonald, T. J.; Nann, T. Trends in Aluminiumbased Intercalation Batteries. Adv. Energy Mater. 2017, 20, No. 1602093.

(17) Zafar, Z. A.; Imtiaz, S.; Razaq, R.; Ji, S.; Huang, T.; Zhang, Z.; Huang, Y.; Anderson, J. A. Cathode Materials for Rechargeable Aluminum Batteries: Current Status and Progress. J. Mater. Chem. A 2017, 5, 5646-5660.

(18) Fu, L.; Li, N.; Liu, Y.; Wang, W.; Zhu, Y.; Wu, Y. Advances of Aluminum Based Energy Storage Systems. Chin. J. Chem. 2017, 35, $13-20$.

(19) Hudak, N. S. Chloroaluminate-doped Conducting Polymers as Positive Electrodes in Rechargeable Aluminum Batteries. J. Phys. Chem. C 2014, 118, 5203-5215.

(20) Stadie, N. P.; Wang, S.; Kravchyk, K. V.; Kovalenko, M. V. Zeolite-Templated Carbon as an Ordered Microporous Electrode for Aluminum Batteries. ACS Nano 2017, 11, 1911-1919.

(21) Wang, F.; Yu, F.; Wang, X.; Chang, Z.; Fu, L.; Zhu, Y.; Wen, Z.; $\mathrm{Wu}, \mathrm{Y}$.; Huang, W. Aqueous Rechargeable Zinc/Aluminum Ion Battery with Good Cycling Performance. ACS Appl. Mater. Interfaces 2016, 8, 9022-9029.

(22) Auborn, J. J.; Barberio, Y. L. An Ambient Temperature Secondary Aluminum Electrode: Its Cycling Rates and Its Cycling Efficiencies. J. Electrochem. Soc. 1985, 132, 598-601.

(23) Mori, T.; Orikasa, Y.; Nakanishi, K.; Kezheng, C.; Hattori, M.; Ohta, T.; Uchimoto, Y. Discharge/Charge Reaction Mechanisms of $\mathrm{FeS}_{2}$ Cathode Material for Aluminum Rechargeable Batteries at $55^{\circ} \mathrm{C}$. J. Power Sources 2016, 313, 9-14.
(24) Yu, Z.; Kang, Z.; Hu, Z.; Lu, J.; Zhou, Z.; Jiao, S. Hexagonal NiS Nanobelts as Advanced Cathode Materials for Rechargeable Al-Ion Batteries. Chem. Commun. 2016, 52, 10427-10430.

(25) Wang, S.; Yu, Z.; Tu, J.; Wang, J.; Tian, D.; Liu, Y.; Jiao, S. A Novel Aluminum-Ion Battery: $\mathrm{Al} / \mathrm{AlCl}_{3}-[\mathrm{EMIm}] \mathrm{Cl} / \mathrm{Ni}_{3} \mathrm{~S}_{2} @ G$ Graphene. Adv. Energy Mater. 2016, 6, No. 1600137.

(26) Jayaprakash, N.; Das, S. K.; Archer, L. A. The Rechargeable Aluminum-Ion Battery. Chem. Commun. 2011, 47, 12610-12612.

(27) Wang, H.; Bai, Y.; Chen, S.; Luo, X.; Wu, C.; Wu, F.; Lu, J.; Amine, K. Binder-Free $\mathrm{V}_{2} \mathrm{O}_{5}$ Cathode for Greener Rechargeable Aluminum Battery. ACS Appl. Mater. Interfaces 2015, 7, 80-84.

(28) Gu, S.; Wang, H.; Wu, C.; Bai, Y.; Li, H.; Wu, F. Confirming Reversible $\mathrm{Al}^{3+}$ Storage Mechanism Through Intercalation of $\mathrm{Al}^{3+}$ into $\mathrm{V}_{2} \mathrm{O}_{5}$ Nanowires in a Rechargeable Aluminum Battery. Energy Storage Mater. 2017, 6, 9-17.

(29) Chiku, M.; Takeda, H.; Matsumura, S.; Higuchi, E.; Inoue, H. Amorphous Vanadium Oxide/Carbon Composite Positive Electrode for Rechargeable Aluminum Battery. ACS Appl. Mater. Interfaces 2015, 7, 24385-24389.

(30) Wang, W.; Jiang, B.; Xiong, W.; Sun, H.; Lin, Z.; Hu, L.; Tu, J.; Hou, J.; Zhu, H.; Jiao, S. A New Cathode Material for Super-Valent Battery Based on Aluminium Ion Intercalation and Deintercalation. Sci. Rep. 2013, 3, No. 3383.

(31) Geng, L.; Lv, G.; Xing, X.; Guo, J. Reversible Electrochemical Intercalation of Aluminum in $\mathrm{Mo}_{6} \mathrm{~S}_{8}$. Chem. Mater. 2015, 27, 49264929.

(32) Paranthaman, M. P.; Brown, G.; Sun, X.-G.; Nanda, J.; Manthiram, A.; Manivannan, A. A Transformational, High Energy Density, Secondary Aluminum Ion Battery. ECS Meeting Abstracts, 2010; MA2010-02, p 314.

(33) Wang, S.; Jiao, S.; Wang, J.; Chen, H.-S.; Tian, D.; Lei, H.; Fang, D.-N. High-Performance Aluminum-Ion battery with CuS@C Microsphere Composite Cathode. ACS Nano 2017, 11, 469-477.

(34) Eftekhari, A.; Corrochano, P. Electrochemical Energy Storage by Aluminum as a Lightweight and Cheap Anode/Charge Carrier. Sustainable Energy Fuels 2017, 1, 1246-1264.

(35) Fouletier, M.; Armand, M. Electrochemical Method for Characterization of Graphite-Aluminium Chloride Intercalation Compounds. Carbon 1979, 17, 427-429.

(36) Gifford, P. R.; Palmisano, J. B. An Aluminum/chlorine Rechargeable Cell Employing a Room Temperature Molten Salt Electrolyte. J. Electrochem. Soc. 1988, 135, 650-654.

(37) Lin, M.-C.; Gong, M.; Lu, B.; Wu, Y.; Wang, D.-Y.; Guan, M.; Angell, M.; Chen, C.; Yang, J.; Hwang, B.-J.; Dai, H. An Ultrafast Rechargeable Aluminium-Ion Battery. Nature 2015, 520, 324-328.

(38) Wu, Y.; Gong, M.; Lin, M.-C.; Yuan, C.; Angell, M.; Huang, L.; Wang, D.-Y.; Zhang, X.; Yang, J.; Hwang, B.-J.; Dai, H. 3D Graphitic Foams Derived from Chloroaluminate Anion Intercalation for Ultrafast Aluminum-ion Battery. Adv. Mater. 2016, 28, 9218-9222.

(39) Yu, X.; Wang, B.; Gong, D.; Xu, Z.; Lu, B. Graphene Nanoribbons on Highly Porous 3D Graphene for High-Capacity and Ultrastable Al-Ion Batteries. Adv. Mater. 2017, 29, No. 1604118.

(40) Song, Y.; Jiao, S.; Tu, J.; Wang, J.; Liu, Y.; Jiao, H.; Mao, X.; Guo, Z.; Fray, D. J. A Long-Life Rechargeable Al Ion Battery Based on Molten Salts. J. Mater. Chem. A 2017, 5, 1282-1291.

(41) Yang, G. Y.; Chen, L.; Jiang, P.; Guo, Z. Y.; Wang, W.; Liu, Z. P. Fabrication of Tunable 3D Graphene Mesh Network with Enhanced Electrical and Thermal Properties for High-Rate Aluminum-Ion Battery Application. RSC Adv. 2016, 6, 47655-47660.

(42) Zhang, L.; Chen, L.; Luo, H.; Zhou, X.; Liu, Z. Large-Sized FewLayer Graphene Enables an Ultrafast and Long-Life Aluminum-Ion Battery. Adv. Energy Mater. 2017, No. 1700034.

(43) Jiao, S.; Lei, H.; Tu, J.; Zhu, J.; Wang, J.; Mao, X. An Industrialized Prototype of the Rechargeable $\mathrm{Al} / \mathrm{AlCl}_{3}^{-}[\mathrm{EMIm}] \mathrm{Cl} /$ Graphite Battery and Recycling of the Graphitic Cathode into Graphene. Carbon 2016, 109, 276-281.

(44) Sun, H.; Wang, W.; Yu, Z.; Yuan, Y.; Wang, S.; Jiao, S. A New Aluminium-Ion Battery with High Voltage, High Safety and Low Cost. Chem. Commun. 2015, 51, 11892-11895. 
(45) Wu, M. S.; Xu, B.; Chen, L. Q.; Ouyang, C. Y. Geometry and Fast Diffusion of AlCl4 Cluster Intercalated in Graphite. Electrochim. Acta 2016, 195, 158-165.

(46) Jung, S. C.; Kang, Y.-J.; Yoo, D.-J.; Choi, J. W.; Han, Y.-K. Flexible Few-Layered Graphene for the Ultrafast Rechargeable Aluminum-Ion Battery. J. Phys. Chem. C 2016, 120, 13384-13389.

(47) Gao, Y.; Zhu, C.; Chen, Z.; Lu, G. Understanding Ultrafast Rechargeable Aluminum-Ion Battery from First-principles. J. Phys. Chem. C 2017, 121, 7131-7138.

(48) Agiorgousis, M. L.; Sun, Y.-Y.; Zhang, S. The Role of Ionic Liquid Electrolyte in an Aluminum-Graphite Electrochemical Cell. ACS Energy Lett. 2017, 2, 689-693.

(49) Bhauriyal, P.; Mahata, A.; Pathak, B. The Staging Mechanism of $\mathrm{AlCl}_{4}$ Intercalation in a Graphite Electrode for an Aluminium-Ion Battery. Phys. Chem. Chem. Phys. 2017, 19, 7980-7989.

(50) Bhauriyal, P.; Mahata, A.; Pathak, B. A Computational Study of a Single-Walled Carbon-Nanotube-Based Ultrafast High-Capacity Aluminum Battery. Chem. - Asian J. 2017, 12, 1837.

(51) Kravchyk, K. V.; Wang, S.; Piveteau, L.; Kovalenko, M. V. Efficient Aluminum Chloride-Natural Graphite Battery. Chem. Mater. 2017, 29, 4484-4492.

(52) Wang, D.-Y.; Wei, C.-Y.; Lin, M.-C.; Pan, C.-J.; Chou, H.-L.; Chen, H.-A.; Gong, M.; Wu, Y.; Yuan, C.; Angell, M.; Hsieh, Y.-J.; Chen, Y.-H.; Wen, C.-Y.; Chen, C.-W.; Hwang, B.-J.; Chen, C.-C.; Dai, $\mathrm{H}$. Advanced Rechargeable Aluminium Ion Battery with a High-quality Natural Graphite Cathode. Nat. Commun. 2017, 8, No. 14283.

(53) Frost, R. The Recovery of Kish Graphite from Secondary Sources. M.Res. Thesis, University of Birmingham: Birmingham, 2015.

(54) Inagaki, M.; Kang, F. Materials Science and Engineering of Carbon: Fundamentals; Butterworth-Heinemann: Oxford, 2014; Chapter 2, pp 17-217.

(55) Moradi, B.; Botte, G. G. Recycling of Graphite Anodes for the Next Generation of Lithium Ion Batteries. J. Appl. Electrochem. 2016, 46, 123-148.

(56) Sri Devi Kumari, T.; Jebaraj, A. J. J.; Raj, T. A.; Jeyakumar, D.; Kumar, T. P. A Kish Graphitic Lithium-insertion Anode Material Obtained from Non-biodegradable Plastic Waste. Energy 2016, 95, 483-493.

(57) Pillot, C. In Battery Market Development for Consumer Electronics, Automotive, and Industrial: Materials Requirements and trends, Advanced Automotive Battery Conference, February 5-7, 2014.

(58) Clark, R. In The Exponential Growth of the Lithium-Ion Battery Market and Its Impact on Global Graphite Supply, International Lithium \& Graphite Conference, November 3-4, 2016.

(59) Shannon, R. Revised Effective Ionic Radii and Systematic Studies of Interatomic Distances in Halides and Chalcogenides. Acta Crystallogr., Sect. A 1976, 32, 751-767.

(60) Wissler, M. Graphite and Carbon Powders for Electrochemical Applications. J. Power Sources 2006, 156, 142-150.

(61) Dahn, J. R.; Zheng, T.; Liu, Y.; Xue, J. S. Mechanisms for Lithium Insertion in Carbonaceous Materials. Science 1995, 270, 590593.

(62) Dresselhaus, M. S.; Dresselhaus, G. Intercalation Compounds of Graphite. Adv. Phys. 2002, 51, 1-186.

(63) Schmuelling, G.; Placke, T.; Kloepsch, R.; Fromm, O.; Meyer, H.-W.; Passerini, S.; Winter, M. X-ray Diffraction Studies of the Electrochemical Intercalation of bis(trifluoromethanesulfonyl)imide Anions into Graphite for Dual-ion Cells. J. Power Sources 2013, 239, 563-571.

(64) Zhao, Y.; VanderNoot, T. J. Electrodeposition of Aluminium from Nonaqueous Organic Electrolytic Systems and Room Temperature molten salts. Electrochim. Acta 1997, 42, 3-13.

(65) Jiang, T.; Chollier Brym, M. J.; Dubé, G.; Lasia, A.; Brisard, G. M. Electrodeposition of Aluminium from Ionic Liquids: Part IElectrodeposition and Surface Morphology of Aluminium from Aluminium Chloride $\left(\mathrm{AlCl}_{3}\right)$-1-ethyl-3-Methylimidazolium Chloride ([EMIm]Cl) Ionic Liquids. Surf. Coat. Technol. 2006, 201, 1-9.
(66) Abbott, A. P.; Harris, R. C.; Hsieh, Y.-T.; Ryder, K. S.; Sun, I. W. Aluminium Electrodeposition under Ambient Conditions. Phys. Chem. Chem. Phys. 2014, 16, 14675-14681.

(67) Jiao, H.; Wang, C.; Tu, J.; Tian, D.; Jiao, S. A Rechargeable AlIon Battery: $\mathrm{Al} /$ molten $\mathrm{AlCl}_{3}$-Urea/Graphite. Chem. Commun. 2017, 53, 2331-2334.

(68) Angell, M.; Pan, C.-J.; Rong, Y.; Yuan, C.; Lin, M.-C.; Hwang, B.-J.; Dai, H. High Coulombic Efficiency Aluminum-Ion Battery using an $\mathrm{AlCl}_{3}$-Urea Ionic Liquid Analog Electrolyte. Proc. Natl. Acad. Sci. U.S.A. 2017, 114, 834-839.

(69) Reddy, T. Linden's Handbook of Batteries, 4th ed.; McGraw-Hill Education: New York, 2010

(70) Chockla, A. M.; Klavetter, K. C.; Mullins, C. B.; Korgel, B. A. Solution-Grown Germanium Nanowire Anodes for Lithium-Ion Batteries. ACS Appl. Mater. Interfaces 2012, 4, 4658-4664. 